\begin{tabular}{ccc}
\hline & International Journal of Engineering \& Technology, $7(4.1)(2018) 109-112$ \\
SPC & International Journal of Engineering \& Technology \\
\hline
\end{tabular}

\title{
Integrating Geometry in Teaching Square of A Binomial - A Lesson Study
}

\author{
Mark Gerald Cerezo*, Karlo Cristobal, Angelo Ferrer, Helen Mae Moreno, Nico Ocampo, Levi Elipane \\ De La Salle University, Manila \\ *Corresponding author E-mail: mark_gerald_cerezo@dlsu.edu.ph
}

\begin{abstract}
This paper intends to discuss the benefits of doing lesson studies in order to improve teaching practice in Mathematics. Fifteen Grade 8 students from a private school in the National Capital Region, Philippines participated in the study. The group followed the cycle of planning the lesson, implementing, and discussing what transpired from teaching the research lesson. The lesson study is about integrating geometry in obtaining the square of a binomial. After planning the lesson and implementing what has been discussed, it has been agreed upon that the objective of the lesson has been met, and that is to relate areas in squaring a binomial. Afterwards, a post-conference discussion was done. It has been emphasized that in order to teach Mathematics effectively and efficiently, a teacher must consider and be aware of the appropriateness of a lesson given a limited amount of time. Additionally, highlighting wrong answers must be done so that students will be able to process what caused those errors and in turn they will be able to avoid those mistakes. Lastly, it is also evident that a teacher should craft his or her skills in the art of questioning. Thus, conducting lesson studies improve teaching practices in mathematics.
\end{abstract}

Keywords: Area; Art of questioning; Geometry; Lesson study; Square of a binomial.

\section{Introduction}

Mathematics plays an integral role in the Philippine Education. However, there are various challenges that beset Filipino Math teachers today, ranging from the curriculum being followed in the country, to the teaching pedagogy being implored. In this research paper, the integration of Geometry and Algebra is explored through Lesson study. The interplay of two different Mathematical perspectives in teaching the lesson on Squaring of a Binomial is the lesson research which targets to help aid teachers in creating effective critical lessons through collaboration and constructive criticism in a Lesson Study, a tool for professional development and leveraging Mathematical pedagogy.

\subsection{Mathematics in the Philippine context}

In accordance with Republic Act 10533 also known as the Enhanced Basic Education Act of 2013, the Philippines follows the Enhanced $\mathrm{K}$ to 12 Program in which the overall design of the curriculum across Grades 1 to 10 is actually the Spiral Progression Approach [1]. This type of curriculum entails that the learners must revisit prior knowledge, continuously build upon what was learned previously, and effectively relate new knowledge or skills with their existing one, thus, enabling learners to master the necessary competencies [2].

Mathematics, as an integral subject, is said to provide opportunities for individuals to develop skills and attitudes needed for effective participation in everyday living and prepare them for further education and the world of work so that they make worthwhile contributions to the society at large [3]. According to the Mathematics Framework for Philippine Basic Education provided by the Science Education Institution of the Department of Science and Technology and the Philippine Council of Mathematics Teacher Education
(MATHTED), in the Philippine Education, Mathematics has the following roles: facilitating participation in productive life activities, providing a way of making sense of the world, serving as a means of communication and operating as a gateway to national progress [4]. This capitalizes the importance of student learning in Mathematics.

\subsection{Math teachers in the Philippines}

To be able to carry out a critical lesson such as the integration of Algebra and Geometry, the teacher must be able to create a learning environment which is conducive for learning. this include the teaching pedagogy, materials and manipulatives to be used (if any), and the utilization of appropriate assessment. In the Philippine context of Mathematics teachers, according to principle, a deep understanding of mathematics requires a variety of tools for learning [4]. This highlights the need for creativity from the part of the Mathematics teachers, to be able to contextualize abstract lessons and to localize for deeper meaning-making. In spite of this Philippine principle in Mathematics, it must also be taken into consideration how Mathematics is actually taught in the country.

In general, a mathematics class in the Philippines has a setup where the teacher explains and asks questions addressed to the whole class [5]. Group work done in class are usually on the lower cognitive level. When students communicate mathematics, they can seldom discuss with the desired understanding of concepts expected from them [3]. The teacher plays an important role in these classroom setups. The Teacher Education and Development Study in Mathematics (TEDS-M) where 17 countries, including the Philippines, participated, it was reported that in terms of quality assurance, teacher education in the Philippines does not fare well. The math teachers, in specific, are near the bottom rank [6]. Teachers in the Philippines do not only show low math knowledge during exams, 
they also do poorly in the tests measuring how well they can teach math [6].

\subsection{Lesson study as tool in developing critical lessons for mathematics}

Lessons with critical approaches require intricate detailing of instructions and questions. These types of lessons must be developed properly, and one of the most effective lesson plan development is through Lesson Study (LS). According to Anfara, Lenski, \& Caskey, Lesson Study is an approach in professional development that originated in Japan and is widely used for more than a century, a method which focuses on improving the teaching-learning process of a particular lesson through teacher-collaboration for a lesson research [7]. For the topic which intertwines algebra and geometry, the LS approach in developing the lesson would allow observers to look at the various aspects of the teaching-learning process to maximize the acquisition of competencies by the students. Lesson study has the ability to allow teachers to realize opportunities for self-discovery and democratic ways of learning, thus, providing avenues for effective professional development [8]. With the data regarding the level of mathematics teachers in the Philippines, it is integral to bring about improvements in the educational system. Lesson study as an avenue for professional growth requires collaborative approach in the development of lessons, openness to collegial debate and constructive criticisms, as well as partnerships with government or non-government agencies as important elements [9].

\section{Methodology}

The lesson study group asked 15 Grade 8 students from School of Everlasting Pearl, Inc. in Antipolo, Rizal. This class of 15 students were mixed with boys and girls. The research lesson has been decided to integrate geometry, specifically areas of squares and rectangles, to the derivation of the equation in squaring of a binomial. The adviser and some math teachers from their school accompanied them to observe the conduct of the lesson study.

\subsection{Planning}

The lesson study group had a two-week preparation for their research lesson. As agreed upon by the members, the main objective of the lesson was to relate geometry to the topic squaring of binomials. Specifically, the lesson intended to relate areas of squares and rectangles to derive the formula of squaring binomials without using the FOIL method, (that is the summation of the product of the first terms, product of the outer terms, product of the inner terms, and product of the last terms). The group focused on deriving the product of $(\mathrm{A}+\mathrm{B})^{2}$. Additionally, $(\mathrm{A}-\mathrm{B})^{2}$ was also included for variation.

Manipulatives were created to concretize the understanding of the binomial square to achieve the objective of relating geometry to the research lesson. These manipulatives were improvised by the group from folders and cartolinas. The aim of the manipulatives was to let the students form a 10 inches by 10 inches square out of the smaller squares and rectangles. The group determined the sizes of the manipulatives in such a way that the students should be able to form 5 squares with dimensions 10 inches by 10 inches. Starting from five big squares, each of which having 10 inches as its side, the sides are cut along the surface to obtained two squares and two rectangles. An example of manipulatives used by the students is shown figure 1.

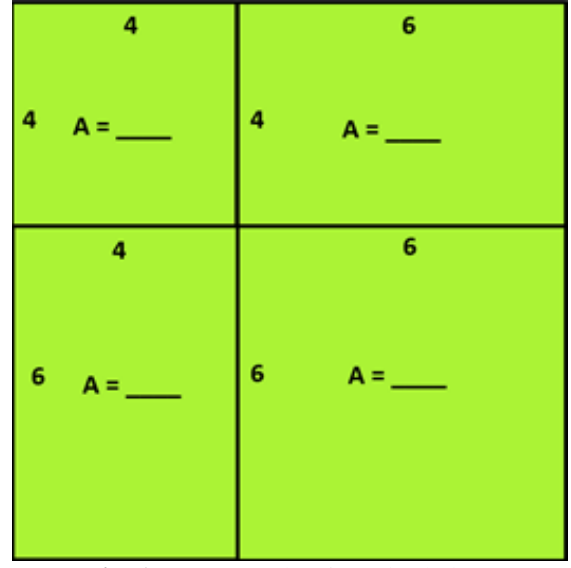

Fig. 1: An example of manipulatives

The partitioning of the sides are all the five possible pairs of addends that will add up to 10 . The combinations will be $(1+9),(2+$ $8),(3+7),(4+6)$, and $(5+5)$. One of these 10 inches by 10 inches' big squares will be composed of a small square with dimensions 9 inches by 9 inches, another smaller square with dimensions 1 inch by 1 inch, and two congruent rectangles with dimensions 1 inch by 9 inches. Examples of these combinations are shown in figure 2.

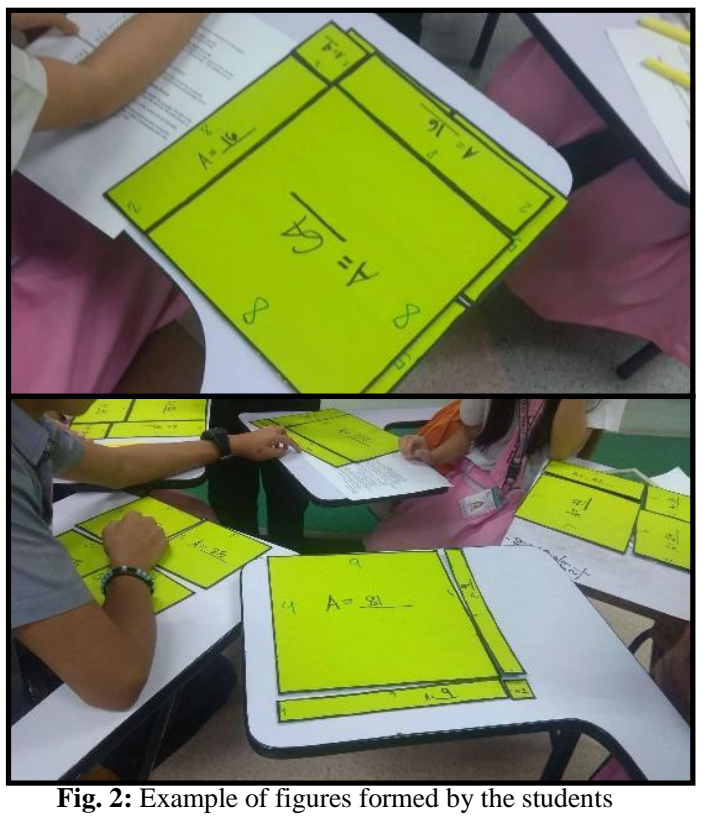

The lesson study group wrote the dimensions of the figures on the side for the students to be able to compute for the areas. A space is provided in the middle for the students to be able to write their computed area.

Additionally, the researchers also made a lesson plan for their research lesson. The lesson plan included the parts as Motivation, Lesson Proper and Activity, Processing, Conclusion, and Assessment. These parts are indicated for discussion during the conduct of the research lessons.

\subsection{Implementation}

In the motivation part, the teacher conducted a quiz bee composed of only 5 questions. The aim of the quiz bee was for the students to recall their knowledge on squares, rectangles, their areas, and multiplying algebraic expressions. One of the questions was: Find the area of the rectangle whose length is $2 \mathrm{x}+1$ and whose width is $3 \mathrm{x}$ +2 .

During the lesson proper, the teacher asked the students to perform the activity. The goal of the activity was for the students to form five big squares from the pool of squares and rectangles which were 
provided per group. They were also asked to compute for the areas of the different figures. It took a lot of time for the students to come up with the five big squares. They tried several strategies to form squares but they were not sure if those figures were indeed squares. During the processing, students were asked to justify their answers. Generally, the students came up with the fact that they should form a big square that has an area of 100 sq. units. The strategy that they used was to come up with the sum of 100 by adding the areas of the smaller figures. As the teacher and the students processed their answers, the students were able to identify that in each set, the dimensions will just end up to be 10 inches by 10 inches. The students then generalized that

$$
(A+B)^{2}=A^{2}+2 A B+B^{2} .
$$

The teacher also tackled the derivation of the equation

$$
(A-B)^{2}=A^{2}-2 A B+B^{2} .
$$

This was done by having a big square with side measuring $A$ units and each side reduced to $B$ units. The remaining figure will then be a square with side measuring $(\mathrm{A}-\mathrm{B})$ units. Although the goal was to relate geometry in deriving this formula, one student already came up with the answer by using the rule obtained from the activity of forming big squares. Both formulas are confirmed using the FOIL method.

The students were able to come up with equation (1) and equation (2). They concluded that the square of a binomial is just equal to the sum of the square of the first term, twice the product of the first and second term, and the square of the second term. After discussing the lesson, the teacher gave a five-item quiz to determine if the students understood the lesson.

\subsection{Post-discussion}

After the lesson, a post-lesson conference immediately followed which was attended by the researchers and the observers to evaluate the research lesson. The researchers were given an opportunity to talk about their initial plans and reflections about the activity. The observers were also asked to give their insights, comments and suggestions regarding the research lesson.

\section{Results and discussions}

After the research lesson was conducted, a post-lesson conference was held together with the rest of the group members, some observers and their professor. During this conference, the members and the observers gave feedbacks and insights about the teacher, the lesson proper, the way the students interacted and other concerns they might have seen during the demo teaching. Through this discussion, the strengths and weaknesses of the research lesson were highlighted which were all beneficial for the improvement of teaching strategies, and lesson development as a whole. The group was able to categorize everything that was mentioned during the discussion into three categories.

\subsection{Decision-making}

One of the most glaring concerns that was experienced by the researchers is the extension of time for each part of the lesson. Initially, the researchers prepared a lesson that is good for one hour but it had to be extended to about an hour and a half. Table 1 shows the actual time the lesson started and ended and the minutes spent for each part of the lesson.
Table 1: Time Table of the Research Lesson

\begin{tabular}{cccc}
\hline $\begin{array}{c}\text { Time } \\
\text { started }\end{array}$ & $\begin{array}{c}\text { Time } \\
\text { ended }\end{array}$ & Activity & Minutes \\
\hline $6: 38 \mathrm{pm}$ & $6: 39 \mathrm{pm}$ & $\begin{array}{c}\text { Daily Routine (Prayer, } \\
\text { Greetings, etc) }\end{array}$ & 1 \\
$6: 39 \mathrm{pm}$ & $6: 53 \mathrm{pm}$ & $\begin{array}{c}\text { Review of previous topic } \\
\text { (Quiz Bee) }\end{array}$ & 14 \\
$6: 53 \mathrm{pm}$ & $7: 37 \mathrm{pm}$ & $\begin{array}{c}\text { Exploratory Activities } \\
\text { (Puzzles) }\end{array}$ & 44 \\
$7: 37 \mathrm{pm}$ & $8: 08 \mathrm{pm}$ & $\begin{array}{c}\text { Lesson Proper (Square of a } \\
\text { Binomial) }\end{array}$ & 31 \\
$8: 08 \mathrm{pm}$ & $8: 17 \mathrm{pm}$ & Assessment (Seatwork) & 9 \\
\hline
\end{tabular}

The extension of time for some parts of the lesson may be attributed to several reasons. First, the students and the teacher were not familiar with each other. The researchers chose a topic for grade 8 students which they deemed best for the strategy and approach they wanted to employ. While most of these students were knowledgeable about the topic, the time extension particularly in the review and exploratory activity part could have been lessened had the researchers been more careful in deciding which questions to ask to elicit responses that would serve as springboard to the actual lesson. While the observers commented that the activity was

very good and was something new compared to the usual approach in teaching the topic "Square of a Binomial", the teacher could have also been more mindful of the time and could have skipped some parts of the activity. Second, one of the comments raised by the observers was about the length of the topic. The group opted to discuss the equations (1) and (2). Some observers commented that in reality discussing both formulas might not be enough in one session. On the other hand, one observer asked the group why the form (-A B $)^{2}$ was not included in the discussion. The teacher and his group mates agreed to exclude this form for the mean time because of time constraint and thought that this might just be discussed in the next session. The group also opted not to include $(-\mathrm{A}-\mathrm{B})^{2}$ because it would not be possible to answer questions in this form using the manipulatives they have prepared since they are dealing with areas of square and rectangles and only considered positive values for the time being. Lastly, it could be observed that some students were shy in answering and asking questions. According to the observers, the instruction of the teacher during the activity was a bit vague which is why some of the students had a hard time doing it. An observer mentioned that teachers should be able to decide on what intervention to use so that the students could answer correctly and understand the lesson better.

The post-lesson conference gave the researchers a better picture and wider perspective of the things to decide on when preparing and teaching a lesson. The researchers should have been more careful in deciding which topic or topics to focus on in a lesson. It would have done the researchers good had they focused on $(A+B)^{2}$ and excluded $(\mathrm{A}-\mathrm{B})^{2}$ since it brought a little confusion on the part of the students and extended a little time in the discussion. Also, as mentioned above, much of the time was spent during the exploratory activity. It would have been better if the researchers thought of other ways in facilitating the exploratory activity without spoonfeeding and resulting to metamathematical shift. The details and instructions of the exploratory activity should have been given more attention to. Lastly, the level of difficulty of the questions given to the students in the recall part should also have been considered more thoroughly since it would serve as the springboard to the actual lesson.

Decision-making is one of the things that a teacher must continually improve on - from preparing the lesson, thinking of strategies and approach to utilize, until the actual teaching.

\subsection{Highlighting wrong answers}

It is quite normal that there would be wrong answers during discussion. The natural tendency of teachers is to veer away from these answers and try to focus on the correct answers. During the discus- 
sion, it was mentioned that wrong answers should also be highlighted and that it is a good feedback milieu. Commonly, if a student answered incorrectly, the teacher would say "Are there any other answers?", which also happened during the research lesson. Highlighting correct answers is as crucial as highlighting wrong answers This is because students think and process information differently. It was suggested during the discussion that if a student answered incorrectly, the teacher could ask the student to explain why he got that answer. This is by no means to embarrass the students but this is to understand how the student understood or misunderstood the lesson. This would also help the teacher clarify things that may be unclear to the other students. In the exploratory activity, some students were unsure if the figures they formed were indeed squares. One group formed a "square" using two 7 inches by 3 inches' rectangles, one 3 inches by 3 inches square and a 6 inches by 6 inches. Their figure looked like a square but was actually wrong. Highlighting their wrong answer could help them process better and discover why their answer was incorrect.

Giving correct and incorrect answers, examples and non-examples would help the students better understand a topic. This would also aid the teacher in drawing out and correcting any misconceptions on the part of the learners.

\subsection{Art of questioning}

Giving information is as important as asking questions. During the post-lesson discussion, the observers applauded that the teacher was able to ask relevant questions to the students that led to the right answers. For example, when some of the students were having a hard time figuring out their activity, the teacher asked them "How do you know that that is a square?" and "What makes a square, square?" Through these questions, the students challenged their own idea of what they know about a square. They found out that just because their figures looked like a square doesn't mean that they were indeed squares. This is when they used the measurement of the sides of the figures and tried to form a square. An observer also mentioned that the teacher was not spoon-feeding his students but was actually helping him by asking more questions until they figure out the correct answers. However, some observers noted that the activity could have been better and the lesson could have improved had the teacher asked better questions when he was recalling the previous topics. In the quiz bee, which is part of the recall, instead of just reviewing the FOIL method, they suggested that there should have been questions about the area of a square and a rectangle.

Lastly, one observer asked if the objectives were met during the lesson proper. All the researchers agreed that they were able to meet the objectives. Although, there had to be time extension, they were able to execute their plan, which was to use the concept in geometry about the area of a square and rectangle in solving for the square of a binomial.

\section{Conclusion}

The lesson study provides opportunities to teachers to improve their quality of teaching. Through collaboration, teachers' suggestions on how to go about the lesson such as the questions to be used in review and assessment, possible questions and concerns that will arise within the students' minds, instructions of the activity and many others. Moreover, the lesson study becomes a venue for teachers to learn the mathematical concepts in a greater measure, understand it more deeply and become more aware of the important things that need to be emphasized during the lesson proper.

The researchers find the lesson study to be very effective and helpful in improving their craft as a teacher because they become more aware of the things they have to improve such as writing a lesson plan, the teaching strategies they want to employ and the actual delivery of the lesson. The researchers are challenged to look for more teaching strategies that they can use in teaching different topics in
Mathematics. Moreover, the researchers find conducting a lesson study to be very helpful but not doable every time because not only it is time-consuming but it would also require a lot of time for preparation and evaluation. This can probably be done at least every quarter to ensure that teachers will continue to develop and grow as a professional. The researchers also agree that there is power in collaboration. Teachers should collaborate and help each other to improve the lesson development. It gives them more perspective and different styles in teaching. If a teacher works alone without the help and comments of other teachers, the preparation and presentation of lessons become single-faceted and thus would be very prone to errors. Finally, the lesson study allowed the teacher to go out of his comfort zone and realize the importance of teamwork. He learned that one can improve his teaching practice through conducting lesson studies

In conclusion, teachers should give much care in making decisions in constructing the lesson. Anticipation of possible issues during the class discussion is a helpful activity to be done by the members of the group in order to think of interventions. Additionally, it is important to give attention on wrong answers provided by the students Highlighting incorrect answers is a good opportunity to correct misconceptions and to determine concepts that need to be explained further. Lastly, teachers should improve their questioning skills. Effective questioning is useful in leading the students to the discovery of the concepts that we want them to learn.

\section{References}

[1] Department of Education. (2012). DO 31, S. 2012. Policy guidelines on the implementation of grades 1 to 10 of the $\mathrm{k}$ to 12 basic education curriculum (bec) effective school year 2012-2013.

[2] SEAMEO-INNOTECH. (2012). K to 12 Toolkit: Resource Guide for Teacher Educators, School Administrators and Teachers.

[3] Pascua L, Secondary Mathematics Education in the Philippines Today, Bell, $G(E d)$, Asian Perspectives on Mathematics Education. The University of New England, Australia, (1993).

[4] SEI-DOST \& MATHTED. (2011). Mathematics framework for philippine basic education. Manila: SEI-DOST \& MATHTED

[5] Ulep SA, "Good Mathematics Teaching Practices in the Making: A Philippine Experience", Tsukuba Journal of Educational Study in Mathematics, Vol.25, (2006)

[6] Ingvarson L \& Rowley G, "Quality Assurance in Teacher Education and Outcomes: A Study of 17 Countries", Teacher Education and Development Study in Mathematics (TEDS-M), Vol.46, No.4, (2008), pp.177-193.

[7] Anfara V, Lenski S \& Caskey M, "Using the lesson study approach to plan for student learning", Middle School Journal, Vol.40, No.3, (2009), pp.50-57.

[8] Elipane LE, "Introducing Lesson Study as a Professional Development Model in the Islands of the Philippines", Journal of Computational and Theoretical Nanoscience, doi:10.116/asl.2017.7514, (2017).

[9] Elipane LE, Casalan M., Pangusan M, Joting-Quiman C \& Alentajan J, "Comparing Perceptions on Professional Development: Introducing Lesson Study to Pre-service Teachers", Talent Development and Convergence Education, Seoul, South Korea, (2014). 